\title{
Transit time flow measurement in on-pump and off-pump coronary artery surgery
}

\author{
Christoph Schmitz, MD \\ Osman Ashraf, MD \\ Wolfgang Schiller, MD \\ Claus Jürgen Preusse, MDa \\ Bahman Esmailzadeh, $\mathrm{MD}^{\mathrm{a}}$ \\ James Anthony Likungu, MD \\ Rolf Fimmers, $\mathrm{PhD}^{\mathrm{b}}$ \\ Armin Welz, MD
}

See related editorial on page 634.

From the Department of Cardiac Surgery, ${ }^{\mathrm{a}}$ Heart Center University of Bonn and Institute for Medical Biometry, Informatics, and Epidemiology, ${ }^{\mathrm{b}}$ Bonn, Germany

Received for publication April 25, 2002; revisions requested June 24, 2002; revisions received Aug 27, 2002; accepted for publication Sept 11, 2002.

Address for reprints: Christoph Schmitz, MD, Department of Cardiac Surgery, University of Bonn, Sigmund-Freud-Strasse 25, 53105, Bonn, Germany (E-mail: c.schmitz@uni-bonn.de).

J Thorac Cardiovasc Surg 2003;126:645-50

Copyright () 2003 by The American Association for Thoracic Surgery

0022-5223/2003\$30.00+0

doi:10.1016/S0022-5223(03)00018-7
Objective: Transit time flow measurement is frequently used during coronary artery bypass with and without cardiopulmonary bypass to detect graft dysfunction resulting from technical errors.

Methods: Intraoperative transit time flow measurement measurements of 896 patients requiring surgery for double- or triple-vessel disease were reviewed retrospectively. Six-hundred and ninety-five patients were operated on-pump (Group A: coronary artery bypass with cardiopulmonary bypass), and 201 patients off-pump (Group B: coronary artery bypass without cardiopulmonary bypass). Transit time flow measurement measurements were analyzed for mean flow $(\mathrm{mL} / \mathrm{min})$. In total, measurements of 2247 grafts were analyzed.

Results: Transit time flow measurement flows were lower in coronary artery bypass without cardiopulmonary bypass patients (left internal thoracic artery to left anterior descending artery: Group A, 37 [31, 40] mL/min vs Group B, 24 [20, 26] mL/min; saphenous vein graft to left anterior descending artery: Group A, 46.5 [40, 56] $\mathrm{mL} / \mathrm{min}$ vs Group B, $21[14,57] \mathrm{mL} / \mathrm{min}$. Troponin I release was reduced in the coronary artery bypass without cardiopulmonary bypass patients, with median values of $7.8[7.0,8.3] \mu \mathrm{g} / \mathrm{L}$ in Group A and $1.2[0.9,2.3] \mu \mathrm{g} / \mathrm{L}$ in Group B.

Conclusion: Evaluation of transit time flow measurement is valuable in determining coronary graft patency after coronary artery bypass with cardiopulmonary bypass and coronary artery bypass without cardiopulmonary bypass. Decreased troponin I release suggests a myocardial benefit of coronary artery bypass without cardiopulmonary bypass compared to coronary artery bypass with cardiopulmonary bypass, although the intraoperative transit time flow measurement flow measurements are markedly lower.

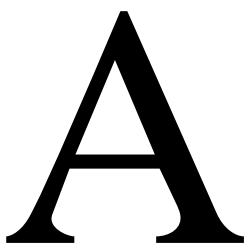

nastomotic quality is a very important issue in coronary artery bypass surgery. Transit time flow measurement (TTFM) has become increasingly popular to detect graft dysfunction resulting from technical errors. ${ }^{1}$ TTFM is a noninvasive Doppler-based technology that generates real-time waveforms of graft flow. ${ }^{2}$ The accuracy and reproducibility of TTFM measurements have been demonstrated in the past. ${ }^{3,4}$

\section{Patients and Methods}

TTFM measurements were prospectively gathered on 896 patients requiring surgery for coronary artery disease from January 2000 to May 2001. All data were collected in a single 
TABLE 1. Patient characteristics

\begin{tabular}{|c|c|c|c|}
\hline & CABG & OPCAB & $P^{*}$ \\
\hline Total number of patients & 695 & 201 & \\
\hline \multicolumn{4}{|l|}{ Preoperative demographics } \\
\hline Mean age (years) & $65.27 \pm 9.77$ & $65.29 \pm 9.79$ & $.90^{*}$ \\
\hline Age $>70$ years $(\%)$ & 38 & 36 & $.45^{*}$ \\
\hline Gender ( $\%$ male $)$ & 77 & 74 & $.77^{*}$ \\
\hline Body mass index $<23(\%)$ & 11 & 15 & $.16^{*}$ \\
\hline Body mass index $>27(\%)$ & 44 & 50 & $.38^{*}$ \\
\hline \multicolumn{4}{|l|}{ Risk factors } \\
\hline Hypertension (\%) & 72 & 69 & $.79^{*}$ \\
\hline Diabetes $(\%)$ & 23 & 20 & $.41^{*}$ \\
\hline $\begin{array}{l}\text { Renal failure (creatinine } \\
>2)(\%)\end{array}$ & 2.2 & 5.0 & $.04^{*}$ \\
\hline $\begin{array}{l}\text { Peripheral vascular } \\
\text { disease }(\%)\end{array}$ & 15 & 13 & $.62^{*}$ \\
\hline Cerebrovascular disease (\%) & 14 & 13 & $.94^{*}$ \\
\hline History of TIA or stroke $(\%)$ & 6.8 & 7.5 & $.75^{*}$ \\
\hline Previous cardiac surgery (\%) & 0.9 & 6.0 & $<.001^{*}$ \\
\hline History of smoking $(\%)$ & 48 & 47 & $.87^{*}$ \\
\hline Hypercholesterolemia (\%) & 63 & 63 & $.99^{*}$ \\
\hline Pulmonary disease $(\%)$ & 12 & 16 & $.20^{*}$ \\
\hline $\begin{array}{l}\text { Dilation of the ascending } \\
\text { aorta }(\%)\end{array}$ & 2.5 & 3.5 & $.44^{*}$ \\
\hline \multicolumn{4}{|l|}{ Clinical presentation } \\
\hline Instable angina (\%) & 12 & 6.0 & $.03^{*}$ \\
\hline Emergent operation (\%) & 8.4 & 2.0 & $.002 \dagger$ \\
\hline $\begin{array}{l}\text { Preoperative on } \\
\text { inotropics (\%) }\end{array}$ & 0.6 & 1.5 & $.19 \dagger$ \\
\hline $\begin{array}{l}\text { Preoperative on } \\
\text { ventilation (\%) }\end{array}$ & 0.7 & 1.5 & $.39 \dagger$ \\
\hline Cardiogenic shock (\%) & 0.4 & 0.5 & $1.0 \dagger$ \\
\hline $\begin{array}{l}\text { Resuscitation within } 48 \mathrm{~h} \\
\text { preop. (\%) }\end{array}$ & 0.7 & 0.5 & $1.0 \dagger$ \\
\hline \multicolumn{4}{|l|}{ EuroSCORE } \\
\hline EuroSCORE $<2(\%)$ & 37 & 41 & $.50^{*}$ \\
\hline EuroSCORE 3-5 (\%) & 41 & 36 & $.37^{*}$ \\
\hline EuroSCORE $\geq 6(\%)$ & 22 & 23 & $.74^{*}$ \\
\hline \multicolumn{4}{|l|}{ Postoperative } \\
\hline 30 -day mortality (\%) & 2.6 & 2.5 & $1.0 \dagger$ \\
\hline
\end{tabular}

TIA, Transient ischemic attack.

${ }^{*}$ Calculated with $\chi^{2}$ test.

tCalculated with Fisher exact test.

clinic database. Sixteen patients $(1.8 \%)$ had to be excluded due to missing data or obvious data entry errors. Six hundred ninety-five patients $(77.6 \%)$ were operated on-pump (Group A: coronary artery bypass grafting [CABG]), and 201 patients (22.4\%) offpump (Group B: off-pump coronary artery bypass [OPCAB]).

A summary of patient characteristics is shown in Table 1. Mean age was $65.27 \pm 9.77$ years in Group A and 65.29 \pm 9.79 years in Group B. Five-hundred and thirty-four patients $(76.8 \%)$ of Group A and 149 patients $(74.1 \%)$ of Group B were male, respectively. Thirty-eight percent of patients in Group A and $36 \%$ of patients in Group B were older than 70 years. A body mass index greater than 27 was observed in $44 \%$ of patients in Group A and 50 of patients in Group B.

There were no statistically significant differences regarding preoperative hypertension, diabetes, peripheral and cerebral vas- cular disease, history of transient ischemic attack or stroke, history of smoking, hypercholesterolemia, pulmonary disease, and dilation of the ascending aorta. Statistically significant differences were seen in preoperative renal failure and previous cardiac surgery, which were more likely in the OPCAB group.

Patients were less likely to be operated on without cardiopulmonary bypass in instable angina or when scheduled as emergency cases. There were no statistically significant differences between preoperative use of inotropics, preoperative ventilation, preoperative cardiogenic shock or patients resuscitated within 48 hours before the operation.

EuroSCORE was retrospectively calculated using the data of the clinic database. ${ }^{5}$ The distribution of patients with various EuroSCOREs is shown in Figure 1. Thirty-seven percent of patients in Group A and $41 \%$ of patients in Group B were in low risk EuroSCOREs $\leq 2,41 \%$ versus $36 \%$ in medium risk EuroSCOREs between 3 and 5, and 22\% versus $23 \%$ in high risk EuroSCOREs $\geq 6$.

Mortality of the CABG patients was $2.6 \%$ versus $2.5 \%$ of OPCAB patients.

TTFM measurements were analyzed for mean flow ( $\mathrm{mL} / \mathrm{min})$. To assess intraoperative myocardial damage postoperative maximum creatine kinase (CK) and cardiac troponin I levels were analyzed for both groups.

All operations were started through a median sternotomy. After incision of the pericardium and inspection of the coronary vessels one or two thoracic arteries were harvested. During the same time the saphenous vein was harvested, if necessary.

In CABG patients, 300 to 400 I.E. heparin per kilogram body weight was administered before transsection of the internal thoracic artery (ITA). The ascending aorta was cannulated near the innominate artery in an area where no calcification could be palpated. Venous backflow was provided by either 1- or 2-stage venous cannula inserted into the right atrial appendage, or 2 separate cannulas put into the superior and inferior venae cavae. After reaching an activated clotting time (ACT) of at least 480 seconds, the patient was put on cardiopulmonary bypass. The body core temperature was lowered to between $30^{\circ} \mathrm{C}$ and $34^{\circ} \mathrm{C}$. Ventricular fibrillation was electrically induced, and the ascending aorta crossclamped. Cardioplegia was administered via a needle vent in the ascending aorta. It consisted of either Bretschneider's ( 2 venous return cannulas) or Buckberg's cold blood cardioplegia (2-stage venous return cannula) according to surgeon preference. The distal vein anastomoses were done first using a running suture of Prolene 7-0, starting from the right coronary artery to the circumflex artery with its branches, and the diagonal branches. The left ITA anastomosis to the left anterior descending (LAD) artery was finally done using a running suture of Prolene 8-0. After removing the crossclamp and internal defibrillation (if necessary) the needle vent was removed and a side-biting clamp was applied. The holes for the central anastomoses were done with an aortic punch of 4.0 to $4.8 \mathrm{~mm}$. The central vein anastomoses were performed using a running suture of Prolene 6-0. After reperfusion and reaching a core temperature of $37^{\circ} \mathrm{C}$ the patient was weaned from cardiopulmonary bypass. TTFM flow of the bypass grafts was assessed before reversing heparin. Generally a pulsatility index $(\mathrm{PI})>5$ led to a revision of the graft. Mean graft flow was documented after reversing heparin with protamine (generally 


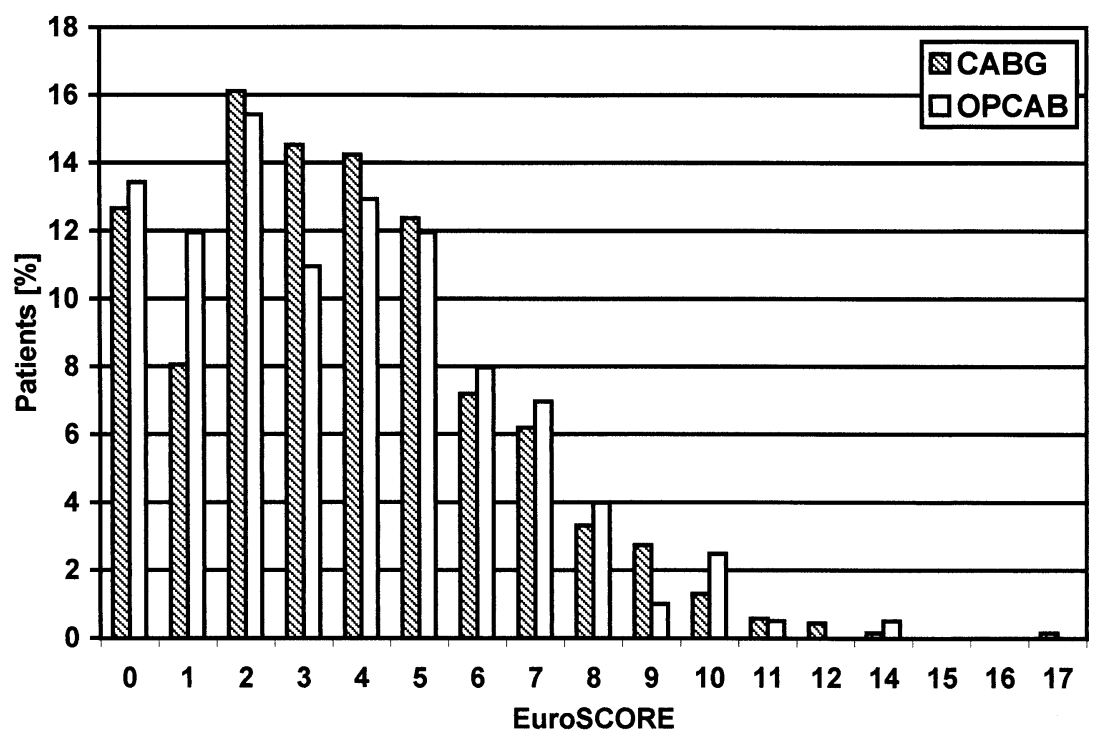

Figure 1. EuroSCORE of patients undergoing CABG or OPCAB surgery.

$80 \%$ of the start dosage of heparin). The sternum was closed using standard sternal wires after putting tubes into the open pleural space and into the pericardium and after temporary pacemaker wires were placed.

In OPCAB patients 200 I.E. heparin per kilogram body weight was administered after finishing the thoracic artery harvesting. Activated clotting time was aimed to be $>200$ seconds. The coronary vessels were presented and stabilized using various stabilizer systems. The order of anastomoses was tailored according to the patient's needs. The anastomotic techniques and sutures did not differ from the techniques and sutures used in patients operated on with cardiopulmonary bypass. In most cases the distal anastomoses were done first. A pledgetted 5-0 Prolene or silicone rubber suture was used to snare the coronary artery temporarily. If no major bleeding was apparent, no distal snare was applied. To clear the surgeon's view, a $\mathrm{CO}_{2}$ blower mister was used. If intended for revascularization, diagonal branches were anastomosed first. Next, the left ITA was anastomosed to the LAD. Generally, ITA flow was assessed before rotation and luxation of the heart. Circumflex arteries and their branches were revascularized subsequently. The last artery to be grafted was in most cases the right coronary artery or the posterior descending artery, respectively. After finishing all distal anastomoses, a side-biting clamp was applied to the ascending aorta and central anastomoses were done. After partially antagonizing heparin ( $0 \%-50 \%$ depending on activated clotting time) TTFM measurements were documented.

\section{Statistical Analysis}

All patient data were exported from our clinic database into StatView 5.0 (SAS Inc, Cary, NC) for analysis. Age is expressed as mean \pm standard deviation. All patient characteristics are shown as a percentage. Comparisons between the 2 groups were performed using either $\chi^{2}$ test, or, if numbers of observed events were $<10$, using Fisher exact test. Flow rates as well as CK and troponin I values are reported as median and $95 \%$ confidence intervals. Comparison of graft flow between patients operated onand off-pump was performed by means of the nonparametric Mann-Whitney $U$ test. Median differences were calculated with $95 \%$ confidence intervals.

\section{Results}

A total of 2247 (1952/295) grafts were analyzed, for a mean of 2.87 (Group A) and 1.47 (Group B) grafts per patient. A left or right thoracic artery to the left anterior descending was used in $80.6 \%$ in Group A and $92.7 \%$ of Group B, and to the diagonal in $14.5 \%$ of Group A and $6.0 \%$ in Group B, respectively. There were 1182 grafts (939 vs 243) to the anterior wall (left anterior descending and diagonal), 699 grafts (679 vs 20) to the left lateral wall (circumflex artery and marginals), and 427 grafts (393 vs 34) to the posterior wall (right coronary artery and posterior descending). The MediStim Model BF 2004 (MediStim AS, Oslo, Norway) was used to assess flow rates in all patients prior to chest closure.

Table 2 and Figure 2 show mean flow rates for each target vessel. In almost all target areas statistically lower mean flow rates were found in patients undergoing OPCAB compared with patients undergoing $\mathrm{CABG}$ surgery. The saphenous vein graft to LAD showed markedly higher flow rates than left or right thoracic artery when anastomosed to the left anterior descending.

Postoperative maximum levels of $\mathrm{CK}$ and troponin I were lower in patients undergoing OPCAB surgery (Figures 3 and 4). 


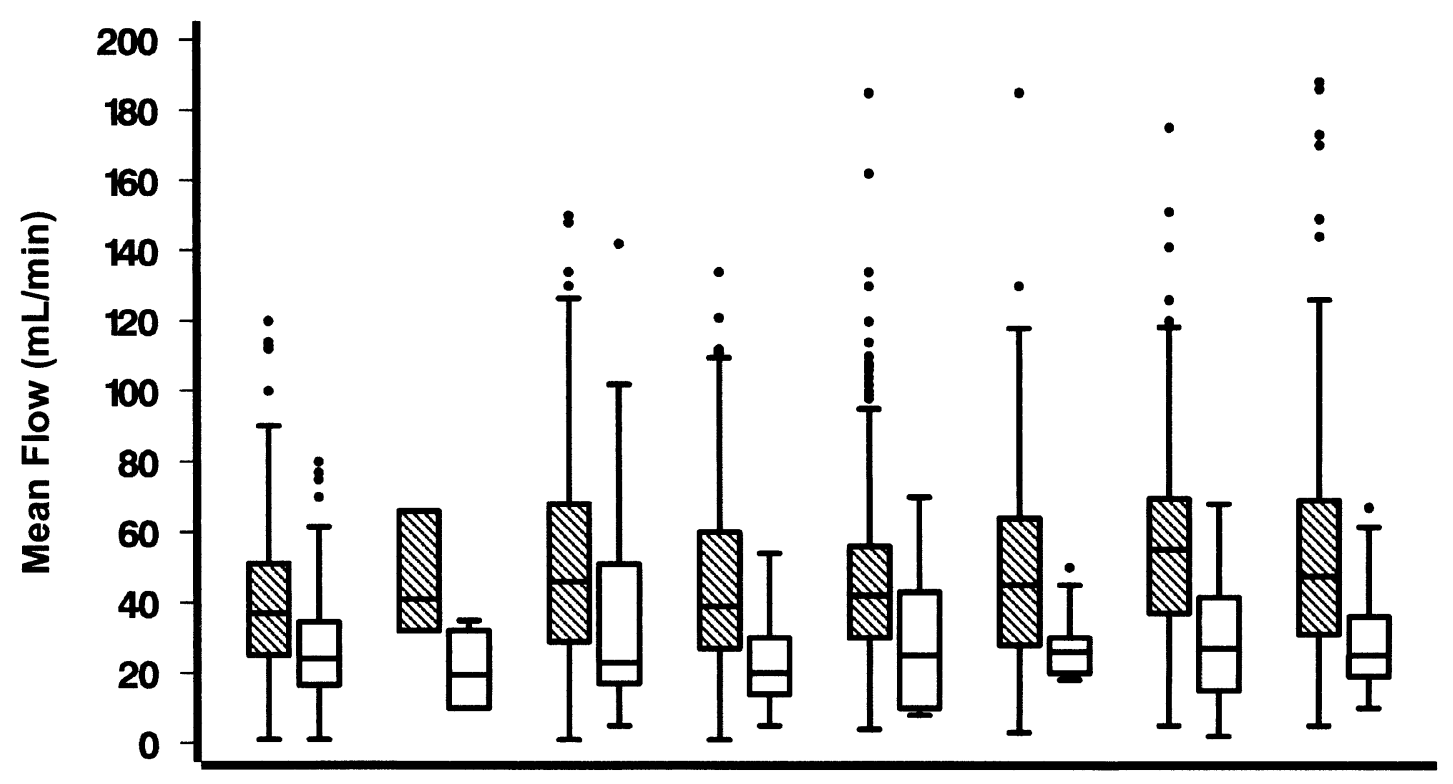

LIMA $>$ LAD RIMA $>$ LAD SVG > LAD SVG $>$ RD SVG $>0 M 1$ SVG $>0 M 2$ SVG $>$ RCA SVG $>$ PDA

Figure 2. Mean flow rates of different grafts to different target vessels in patients undergoing CABG or OPCAB surgery. $L I M A$, Left internal mammary artery; $L A D$, left anterior descending artery; RIMA, right internal mammary artery; $S V G$, saphenous vein graft; $R D$, diagonal branch; $O M$, obtuse marginal branch; $R C A$, right coronary artery; $P D A$, posterior descending artery.

TABLE 2. Mean flow rates of different grafts to different target vessels

\begin{tabular}{|c|c|c|c|c|c|c|c|}
\hline \multirow[b]{2}{*}{ Graft } & \multirow[b]{2}{*}{$\begin{array}{l}\text { Target } \\
\text { vessel }\end{array}$} & \multicolumn{2}{|c|}{ CABG } & \multicolumn{2}{|c|}{ OPCAB } & \multirow[b]{2}{*}{$\begin{array}{c}\text { Median difference } \\
{[95 \% \mathrm{Cl}]}\end{array}$} & \multirow[b]{2}{*}{$P$} \\
\hline & & $\begin{array}{c}\text { Mean flow } \\
(\mathrm{mL} / \mathrm{min}) \pm \mathrm{SD}\end{array}$ & n & $\begin{array}{c}\text { Mean flow } \\
(\mathrm{mL} / \mathrm{min}) \pm \mathrm{SD}\end{array}$ & n & & \\
\hline LITA & LAD & $40.25 \pm 22.92$ & 166 & $27.22 \pm 15.55$ & 108 & $11[7,15]$ & $<.0001$ \\
\hline RITA & LAD & $46.33 \pm 17.62$ & 3 & $21.00 \pm 12.94$ & 4 & $31[-3,56]$ & .1143 \\
\hline SVG & LAD & $53.93 \pm 33.00$ & 126 & $37.79 \pm 34.79$ & 14 & $16[3,33]$ & .0253 \\
\hline LITA & $\mathrm{RD}$ & $24.00 \pm 15.23$ & 6 & $12.50 \pm 3.54$ & 2 & $10[-4,41]$ & .3571 \\
\hline SVG & $\mathrm{RD}$ & $43.71 \pm 23.58$ & 264 & $24.11 \pm 13.24$ & 45 & $17[12,23]$ & $<.0001$ \\
\hline SVG & OM1 & $45.73 \pm 23.80$ & 439 & $29.73 \pm 21.51$ & 11 & $16[4,28]$ & .0144 \\
\hline SVG & OM2 & $48.93 \pm 26.49$ & 145 & $28.33 \pm 11.50$ & 6 & $17[2,36]$ & .0279 \\
\hline SVG & $c X$ & $48.57 \pm 31.21$ & 68 & $43.50 \pm 37.48$ & 2 & $3[-47,50]$ & .8863 \\
\hline SVG & RCA & $56.09 \pm 27.89$ & 158 & $28.75 \pm 19.45$ & 12 & $26[12,39]$ & .0007 \\
\hline SVG & PDA & $53.55 \pm 32.11$ & 221 & $28.24 \pm 16.48$ & 17 & $21[11,33]$ & .0002 \\
\hline
\end{tabular}

LITA, Left internal thoracic artery; RITA, right internal thoracic artery; SVG, saphenous vein graft; $L A D$, left anterior descending artery; $R D$, diagonal branch; $O M$, obtuse marginal branch; $C X$, circumflex artery; $R C A$, right coronary artery; $P D A$, posterior desending artery.

\section{Discussion}

Although off-pump coronary artery surgery has been performed for more than a decade, ${ }^{6}$ these techniques are still not generally accepted because of concerns about anastomotic quality ${ }^{7}$ or completeness of revascularization. ${ }^{8}$

Intraoperative assessment of graft quality is very important in order to detect graft failure resulting from technical problems in a very early stage while still being in the operating room and having the chest open. TTFM is increasingly gaining interest because it is fast, reproducible, and easy to use. Alternate methods, such as intraoperative angiography, thermal angiography, probing of the anastomosis, electromagnetic graft flow measurement, and absence of hemodynamic compromise have not been widely used due to major technological expenditures, difficulties in interpretation, missing reproducibility, or simple inaccuracy.

Interpretation of anastomotic quality as a single function of mean graft flow may be difficult. Commonly, low graft flow is considered to be associated with anastomotic errors. However, several authors were able to demonstrate that 


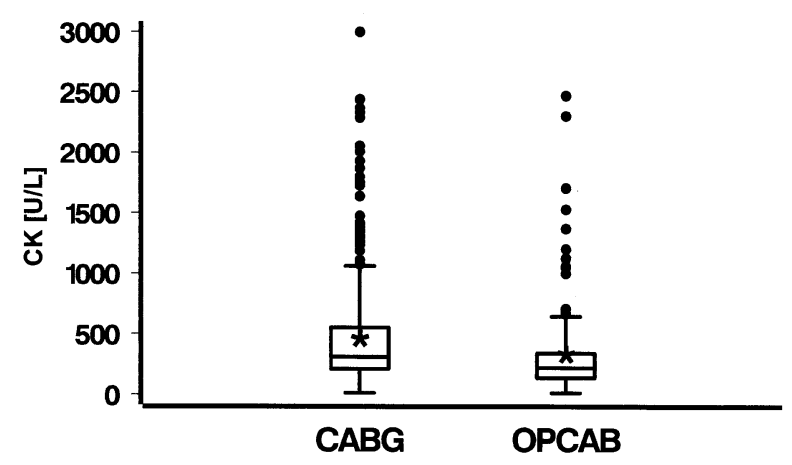

Figure 3. Maximum postoperative CK levels in patients undergoing CABG or OPCAB surgery.

mean flow values do not correlate with clinical outcome or long-term patency. ${ }^{9,10}$ It is also possible to have a patent anastomosis with a low mean graft flow. On the other hand, high mean graft flow is generally felt to confirm a patent anastomosis. But again, it is also possible to have high graft flow with a stenotic anastomosis. Jaber and colleagues ${ }^{11}$ have shown that mean graft flow did not change significantly until graft stenosis was greater than $75 \%$.

In our series, patient characteristics were very similar. Statistically significant differences were found only in previous cardiac surgery and preoperative renal failure (more often in OPCAB patients), and instable angina and patients preoperative on inotropics (more often in CABG patients). These differences emphasize the patient selection policy at our institution, but so far they have not been identified as affecting TTFM flow rates.

The most interesting and unexpected finding in our study was that the overall performance of grafts in off-pump surgery is about half the flow, which can be assessed in grafts after operations with CPB. However, this finding did not lead to an increased myocardial damage during the operation. In contrast, postoperative cardiac enzymes (CKMB and troponin I) were significantly lower in the off-pump group than in the on-pump group. This finding seems to be accepted by most authors. ${ }^{12-14}$

In the beginning of our OPCAB experience the finding of decreased mean flow led to a high graft-revision rate, although flow patterns were very often acceptable. In many cases we were not able to improve the quality of the anastomosis due to the fact that there was no technical error. The decreased mean flow rates compared with the experience from CABG surgery led to a wrong performance rating of the graft, as we did not anticipate such a high impact of the procedure itself.

An explanation for the decreased flow rates in $\mathrm{OPCAB}$ patients might be the procedure itself. It is well documented that CABG surgery on the arrested heart-even with cardioplegia - leads to global ischemia and subsequent acido-

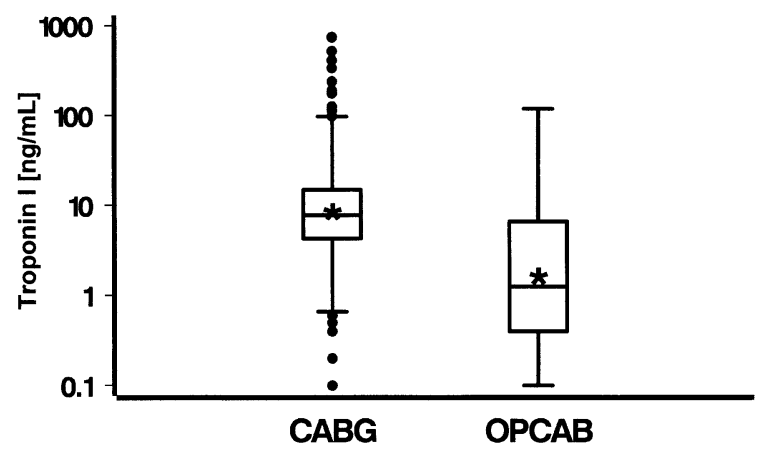

Figure 4. Maximum postoperative troponin I levels in patients undergoing CABG or OPCAB surgery.

sis in the coronary artery system. ${ }^{15}$ During myocardial anaerobiosis the amount of energy obtained from glycolysis is not sufficient to cover the demands of myocardial energy turnover, so that a myocardial energy deficit necessarily develops with progressive duration of ischemia. ${ }^{16}$ The acidosis in the coronary artery system results in vasodilation of the coronary arteries. ${ }^{17}$ In contrast, in OPCAB surgery occlusion of the coronary vessel contributes to a local hypoxia, but generally not to ischemia. Therefore, the vasodilator effect of ischemia is absent. Consequently, flow rates in off-pump coronary artery surgery should be expected to be lower than in on-pump surgery.

A second explanation for the decreased mean flow rates in off-pump coronary artery surgery-which can be assessed in all target areas-might be the use of vasoconstrictors (eg, norepinephrine) to stabilize hemodynamics during rotation and luxation of the heart.

Another finding was the significant flow difference between arterial and venous grafts. Although arterial grafts have much better long-term patency than venous grafts, it is important to recognize that arterial grafts sometimes have a limited ability to supply blood flow at peak myocardial demand. ${ }^{18}$ Flemma and colleagues ${ }^{19}$ showed that blood flow through saphenous vein grafts was 2 to 3 times higher than blood flow through ITA grafts to the same target area (mean arterial and venous graft flow $43 \mathrm{~mL} / \mathrm{min}$ vs 117 $\mathrm{mL} / \mathrm{min}$, respectively). ${ }^{19}$ Hamby and coworkers ${ }^{20}$ demonstrated in an angiographic study, performed 2 weeks after bypass surgery, that ITA graft flow was significantly lower than that of saphenous vein grafts $(46 \pm 16 \mathrm{~mL}$ vs $68 \pm 27$ $\mathrm{mL}$, respectively, $P<.01) .{ }^{20}$

In conclusion, TTFM flow measurement in coronary artery surgery may help to detect graft failure from technical errors. However, in order to correctly judge graft patency intraoperatively, it is obligatory to examine TTFM flow patterns, PI, mean flow rates, and clinical data (eg, electrocardiogram, transesophageal echocardiogram, hemodynamic data) simultaneously, particularly in OPCAB surgery. 


\section{References}

1. D'Ancona G, Karamanoukian HL, Ricci M, Schmid S, Bergsland J, Salerno TA. Graft revision after transit time flow measurement in off-pump coronary artery bypass grafting. Eur J Cardiothorac Surg. 2000; 17:287-93.

2. Lundell A, Bergqvist D, Mattsson E, Nilsson B. Volume blood flow measurements with a transit time flowmeter: an in vivo and in vitro variability and validation study. Clin Physiol. 1993;13:547-57.

3. Dean DA, Jia CX, Cabreriza SE, D'Alessandro DA, Dickstein ML, Sardo MJ, et al. Validation study of a new transit time ultrasonic flow probe for continuous great vessel measurements. ASAIO J. 1996;42: M671-6.

4. Matre K, Birkeland S, Hessevik I, Segadal L. Comparison of transittime and Doppler ultrasound methods for measurement of flow in aortocoronary bypass grafts during cardiac surgery. Thorac Cardiovasc Surg. 1994;42:170-4.

5. Nashef SA, Roques F, Michel P, Gauducheau E, Lemeshow S, Salamon R. European system for cardiac operative risk evaluation (EuroSCORE). Eur J Cardiothorac Surg. 1999;16:9-13.

6. Benetti FJ. Direct coronary surgery with saphenous vein bypass without either cardiopulmonary bypass or cardiac arrest. J Cardiovasc Surg (Torino). 1985;26:217-22.

7. Cooley DA. Con: beating-heart surgery for coronary revascularization: is it the most important development since the introduction of the heart-lung machine? Ann Thorac Surg. 2000;70:1779-81.

8. Jegaden O, Mikaeloff P. Off-pump coronary artery bypass surgery. The beginning of the end? Eur J Cardiothorac Surg. 2001;19:237-8.

9. Canver CC, Cooler SD, Murray EL, Nichols RD, Heisey DM. Clinical importance of measuring coronary graft flows in the revascularized heart. Ultrasonic or electromagnetic? J Cardiovasc Surg (Torino). 1997;38:211-5.

10. Louagie YA, Haxhe JP, Jamart J, Buche M, Schoevaerdts JC. Doppler flow measurement in coronary artery bypass grafts and early postoperative clinical outcome. Thorac Cardiovasc Surg. 1994;42:175-81.

11. Jaber SF, Koenig SC, BhaskerRao B, VanHimbergen DJ, Cerrito PB,
Ewert DJ, et al. Role of graft flow measurement technique in anastomotic quality assessment in minimally invasive CABG. Ann Thorac Surg. 1998;66:1087-92.

12. Peivandi AA, Dahm M, Hake U, Hafner G, Opfermann UT, Loos AH, et al. Patterns and diagnostic value of cardiac troponin I vs. troponin $\mathrm{T}$ and CKMB after OPCAB surgery. Thorac Cardiovasc Surg. 2001; 49:137-43

13. Shiga T, Terajima K, Matsumura J, Sakamoto A, Ogawa R. Minor cardiac troponin $\mathrm{T}$ release in patients undergoing coronary artery bypass graft surgery on a beating heart. J Cardiothorac Vasc Anesth. 2000;14:151-5.

14. Wildhirt SM, Schulze C, Conrad N, Sreejayan N, Reichenspurner H, von Ritter C, et al. Reduced myocardial cellular damage and lipid peroxidation in off-pump versus conventional coronary artery bypass grafting. Eur J Med Res. 2000;5:222-8.

15. Graffigna AC, Nollo G, Pederzolli C, Ferrari P, Widesott L, Antolini R. Continuous monitoring of myocardial acid-base status during intermittent warm blood cardioplegia. Eur J Cardiothorac Surg. 2002; 21:995-1001.

16. Preusse CJ, Gebhard MM, Bretschneider HJ. Interstitial pH value in the myocardium as indicator of ischemic stress of cardioplegically arrested hearts. Basic Res Cardiol. 1982;77:372-87.

17. Ishizaka H, Kuo L. Acidosis-induced coronary arteriolar dilation is mediated by ATP-sensitive potassium channels in vascular smooth muscle. Circ Res. 1996;78:50-7.

18. Taki J, Ichikawa A, Nakajima K, Kawasuji M, Tonami N. Comparison of flow capacities of arterial and venous grafts for coronary artery bypass grafting: evaluation with exercise thallium-201 single-photon emission tomography. Eur J Nucl Med. 1997;24:1487-93.

19. Flemma RJ, Singh HM, Tector AJ, Lepley D Jr, Frazier BL. Comparative hemodynamic properties of vein and mammary artery in coronary bypass operations. Ann Thorac Surg. 1975;20:619-27.

20. Hamby RI, Aintablian A, Wisoff BG, Hartstein ML. Comparative study of the postoperative flow in the saphenous vein and internal mammary artery bypass grafts. Am Heart J. 1977;93:306-15. 